\title{
ECONOMic CAPITAL For CREDIT RISK IN THE TRAdING BOOK
}

\author{
Wynand Smit, Gary van Vuuren and Paul Styger \\ Department of Economics, North-West University
}

Accepted March 2011

\begin{abstract}
The Basel II accord sets out detailed formulations (in its Internal Ratings Based approaches) for determining credit risk capital in the banking book, but until recently, credit risk in the trading-book was largely ignored. The financial crisis in $2007 / 08$ exposed this oversight: woefully inadequate trading book capital led to considerable losses which resulted in, inter alia, the imposition of severe capital requirements on credit riskprone securities in the trading book. Using empirical loss data, this article investigates whether these requirements are appropriate for the trading book and proposes a possible alternative which banks may use to determine economic capital.
\end{abstract}

Key words: Basel II, holding period, credit risk, trading book, economic capital

JEL G21, 32

1

\section{Introduction}

Measuring and managing risk capital in a bank is critical in maintaining global financial stability - especially when large losses occur or in times of high market volatility. It is, therefore, vital that regulatory capital frameworks such as the Basel II accord (designed to measure the requisite retention of risk-sensitive capital) are constantly adapted and improved. The current (Basel II) accord is arguably more risk-sensitive than its predecessor, Basel I, and sets out several methods to determine regulatory risk capital for use by qualifying banks. These methodologies are intended to improve the ability of banks to quantify and manage their risk (Proctor, 2006:1). The implementation of Basel II has corrected numerous weaknesses of Basel I, although the financial crisis in 2007/08 exposed several areas where the accord could be further improved to strengthen the global banking sector (Financial Stability Forum (FSF) and Basel Committee on Bank Supervision (BCBS) Working Group, 2009:5).

Regulatory capital is, however, an accounting concept which does not correspond with banks' internal measure of economic ${ }^{1}$ capital. Major banks have transitioned away from using regulatory capital toward required economic capital as the basis for making a wide variety of decisions (Dvorak, 2005:2), including risk-based pricing, capital budgeting, limit setting, capital-adequacy assessment and performance measurements (Wong, 2008:1). Models and model parameters employed to measure economic capital are chosen completely at banks' discretion while regulatory capital measurement methodologies (e.g. the Foundation and Advanced Internal Ratings Based approaches to credit risk) are fixed with only a few input parameters estimated by practitioners themselves (Zhang et al., 2008:6).

The inflexibility of the regulatory capital approach has recently encountered some industry criticism. This is particularly true for the changes made to trading book regulatory capital in the wake of the financial crisis in $2007 / 08$. Despite the severity of losses incurred from the crisis, banks and industry practitioners have complained about the new charges, arguing that they are unrealistic and highly punitive (HBOS, 2009:2). This article investigates the effect on banks of the introduction of new regulatory capital requirements for - inter alia - credit risk in the trading book (the 'incremental risk charge' or 
IRC) and proposes a methodology for determining a more realistic capital charge for trading book credit risk using empirical loss data accumulated from the recent crisis. Although banks are constrained from a regulatory point of view to use Basel II approaches and most parameters used in Basel II's prescribed approaches, they may still use the methodology proposed here to evaluate their economic capital and so determine an empirical, economic capital estimate.

The remainder of this article is structured as follows: Section 2 presents a literature study which provides the relevant background information for a better understanding of the problem including causes and effects, the Basel committee's response and the industry's reaction to this response. Section 3 introduces the framework of a proposed methodology to alleviate the imposed punitive charges and Section 4 presents the data employed in this study as well as the results obtained. Section 5 discusses the results and concludes the article.

\section{2}

\section{Literature study}

Basel II stipulates how banks should distinguish between their 'banking book' and 'trading book' activities. The trading book comprises positions that are marked-to-market and actively hedged, giving it a more market risk flavour as these positions are rarely held for extensive periods, but are rather intentionally re-sold in the short term (BCBS, 2004:150). Hedged positions offset the component risk elements of other trading book positions. A condition of trading book positions, then, is high liquidity as these positions must be easy to sell and be readily hedged. Basel II has specified the following requirements for positions to qualify for receiving trading book capital treatment (BCBS, 2004:150):

i a transparent and documented trading strategy, approved by senior management must be available; and

ii well-defined policies and procedures designed to actively manage positions in the trading book. These should include the following:
- positions should be managed on a trading desk;

- position limits should be determined and monitored for appropriateness;

- traders should have the right to manage positions within specified limits and according to the approved strategy;

- positions should be marked to market on a daily basis. When marked to model (assets priced according to a market model as some securities - such as Over the Counter (OTC) options - may not be liquid) parameters should be assessed daily;

- positions should be reported to senior management as part of the institution's risk management process;

- positions should be actively monitored according to market information sources including the assessment of quality and availability of market inputs to the valuation process, the level of market turnover, sizes of traded positions, and

iii well-defined policies and procedures should be in place to ensure that trading book positions (including turnover) are monitored against the bank's pre-defined trading strategy.

The banking book embraces all other remaining instruments held by the bank of which loans are the largest. Subject to accrual accounting, the banking book more formally embraces positions that may be considered to have the same characteristics as the traditional loan portfolio where assets are normally held to maturity. Capital requirements for the banking book are, therefore, associated with longer holding periods. From a regulatory perspective, commercial banks hold more capital for assets in the banking book while securities firms hold more capital for trading book assets (Nazareth, 2007).

Traditionally, credit risk dominates the banking book (which is subject to little market risk), whilst the trading book is most prone to market risk (and considered relatively sheltered from credit risk). Market risk has a direct effect on capital and return and has thus always been of concern for financial market participants (Van de Venter, 2000:2). 
Regulators also have a particular interest in this risk type which is an important element in the overall financial health of the banks they regulate. Banks' exposure to market risk is rooted in the probability of unfavourable asset price movements and is measured using value at risk (VaR). Market risk was formally taken to a level of increased importance in 1996 when the BCBS amended the 1988 Basel I framework to include market risk. The capital requirement for the trading book using the Internal Model Approach is, according to Basel I (and largely unchanged in Basel II):

$$
\text { Trading book regulatory capital }=\operatorname{Max}\left(k \times \frac{1}{60} \cdot \sum_{i=1}^{60} V a R_{t-i}, V a R_{t-1}\right)+S R C
$$

where $V_{a R_{t-1}}$ is yesterday's $\mathrm{VaR}, \frac{1}{60} \cdot \sum_{i=1}^{60} V_{a R_{t-i}}$

is the average $\mathrm{VaR}$ measured over the last 60 days and $k$ is a scaling factor determined by local regulators based on their quality assessment of the bank's risk management system (BCBS, 2006:76). This factor ranges from three to four depending on backtesting results of banks' internal models. ${ }^{2}$ Basel II considered this factor as essential to translate daily $\mathrm{VaR}$ estimates into a capital charge where sufficient capital is available to serve as a cushion for potential increasing losses due to unfavourable market conditions (Alentorn \& Markose, 2008:48). Regulators would not have sufficient comfort unless VaR was multiplied by this factor (BCBS, 1995:15). ${ }^{3}$ The capital charge for specific risk - SRC in Equation 1 is intended to protect banks against unfavourable price movements of positions which are the result of factors related to individual issuer and is comparable - but not equivalent - to credit risk (Bakshi, 2004:430). Specific risk includes the risk that an individual debt or equity security varies by more or less than the general market in day-today trading (BCBS, 2005a:3). This includes periods when the entire market is subject to high volatility. Specific risk also covers event risk in which the price of an individual debt or equity security varies sharply relative to the general market. This occurs in events such as takeover bids or other shock events which might include the risk of default. ${ }^{4}$

In 2006, Basel II introduced the treatment of counterparty credit risk in the trading book as follows: Banks are required to calculate the counterparty credit risk charge for OTC derivatives, repo-style and other transactions booked in the trading book, separate from the capital charge for general market risk and specific risk. The risk weights to be used in this calculation must be consistent with those used for calculating the capital requirements in the banking book (BCBS, 2006:164).

Note that this counterparty credit risk charge foreshadowed the far broader implementation of the IRC (to embrace all credit-risky securities and positions, not merely those involving derivatives) in 2009/2010 following from losses incurred due to the financial crisis in $2007 / 08$.

VaR was introduced by JP Morgan at the beginning of the 1990s and it has become established as the most important measure of market risk (Hartz et al., 2006:2295). Berkowitz and O'Brien (2002:1110) evaluated the statistical accuracy of the VaR forecasts to determine the accuracy of banks' trading risk models and found that bank's VaR forecasts were conservative under the Basel II regime. These and other results contributed to the perception that $\mathrm{VaR}$ provided a safe and sufficient level of market risk capital, although $\mathrm{VaR}$ did receive some criticism about issues such as being theoretically deficient (VaR does not compute a worst case scenario: this is the domain of the expected shortfall) and numerically problematic (VaR is not subadditive) (Hartz et al., 2006:2295). Despite the shortcomings of $\mathrm{VaR}$, it was recognised by Basel II and remains the most widely used global market risk measure. The financial crisis in 2007/08, however, changed the perception about VaR. VaR is a backwardlooking risk measure, heavily dependent on the averaging of historical data, so whatever the method used to calculate it, it does not 
sufficiently capture unexpected market shocks as experienced during the financial crisis in $2007 / 08$. This can be observed where sudden losses exceed historical trends such as in Figure 1. The figure shows the rapid increase in daily 99 per cent $\mathrm{VaR}$ (using equally weighted and exponentially weighted moving average volatilities) of the FTSE 100 returns measured since January 1999 (thus embracing long periods of benign calm punctuated by market crises). The volatility during the crisis changed too rapidly for VaR to adequately adapt and thus remain relevant.

\section{Figure 1}

Increase in volatility as a result of the financial crisis in 2007/08 - FTSE100 index returns and 99 per cent $\mathrm{VaR}$ calculated using one year of rolling daily returns

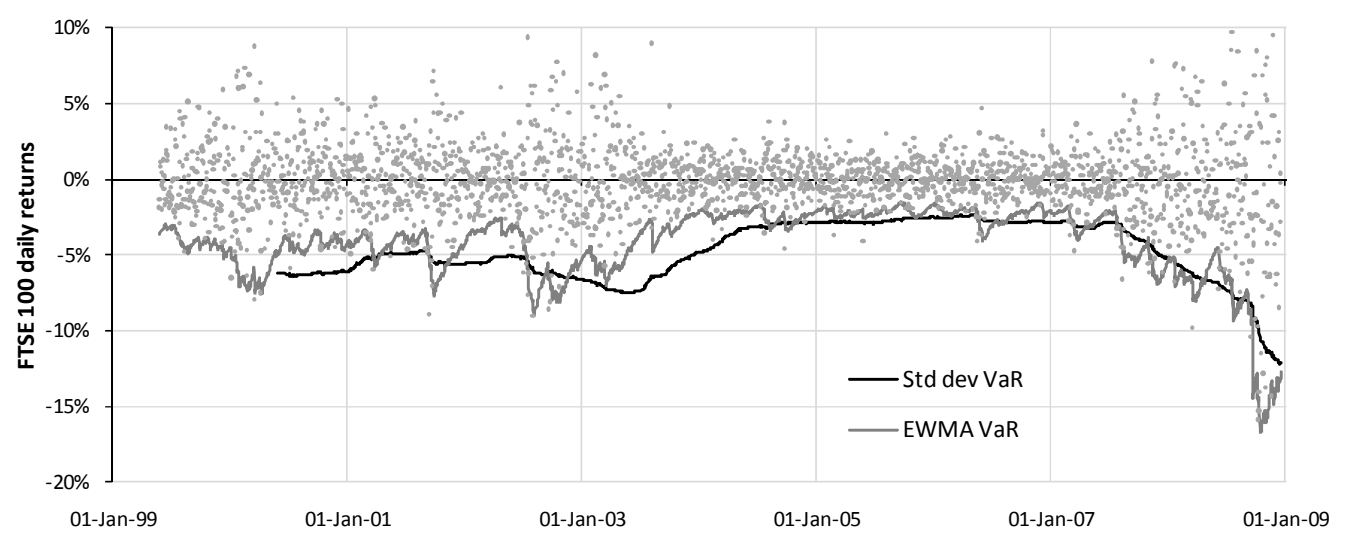

Source: Bloomberg, 2009.

This observation of $\mathrm{VaR}$ is consistent with a report by the Federal Reserve Bank of New York who plotted the average VaR from 2001 to 2008 for Bear Stearns and Lehman Brothers (Adrian \& Shin, 2009:21). A significant VaR increase was experienced from mid 2007 onwards. The increased $\mathrm{VaR}$ for these two investment banks provides further evidence that banks' balance sheets were under considerable stress during this time (Adrian \& Shin, 2009:21). VaR neither anticipated nor reacted quickly enough to stress introduced by the financial crisis in 2007/08 according to Merrill Lynch's (2008:7) third-quarter filing with the US SEC. The BCBS expressed its concern in its comments on the increase in trading losses and VaR exceptions (BCBS, 2007:3).

Implicit in a 99 per cent confidence interval $\mathrm{VaR}$ is the tacit acknowledgment that 1 per cent of losses should exceed the forecast VaR. Exceptions occur when losses exceed forecast $\mathrm{VaR}$ over and above the expected number of such occurrences (Jorion, 2000:130). Given the severity of the crisis that affected financial markets and the increase in market volatility across all actively traded asset classes, larger numbers of banks with significant trading book exposures reported increases in $\mathrm{VaR}$ exceptions. These increases challenged the assumed robustness of VaR models and also exposed flaws in VaR models (one of which was that losses stemmed not only from increased volatility, but also credit from events). Some of the main concerns about VaR and the recent failure of the approach include that it:

- is not designed to measure risk accurately during crisis conditions;

- provides no clarity on events beyond the 99 per cent worst probability of losses;

- measures market risk only and does not, therefore, provide a complete risk overview; and

- is too dependent on historical volatility and therefore has a 'short memor' (Bakhshi, 2007:10). 
The BCBS also anticipated the potential risk of credit events in the trading book as the Basel/IOSCO agreement, reached in July 2005, contained several improvements to the capital regime for trading book positions (BCBS, 2005a:67). Among others, the revisions included a new requirement for banks - the incremental risk charge or IRC - that models specific risk to measure capital that is incremental to any default risk captured in the bank's VaR model. In October 2007, the BCBS (2007) released a document for public comments which introduced guidelines for computing capital for IRC. The proposed guidelines were introduced to banks as the market risk charge at the time was insufficient to cover losses. According to the BCBS (2008:1), the increased losses that occurred during the worst phase of the financial crisis in 2007/08 did not arise from actual defaults, but rather from credit migrations combined with widening of credit spreads and the loss of liquidity (BCBS, 2008:1). An expanded scope for capital charges was therefore needed and the BCBS moved to embed the risk of credit events to take account of banks' exposure to credit-risk related and often illiquid products in the trading book whose risk is not reflected in VaR (BCBS, 2007:1). The IRC was considered to be part of the specific risk component (which up to that point referred to the risk of price movements in an individual company due to specific events that influence the capital charge calculation) (BCBS, 2008:1). Without more specific guidelines, however, IRC was poorly implemented and difficult for regulators to monitor. As a result, the BCBS issued the above mentioned consultative document in which,

the decision was taken in light of the recent credit market turmoil where a number of major banking organisations have experienced large losses, most of which were sustained in banks' trading books. Most of those losses were not captured in the 99 per cent/10-day VaR. Since the losses have not arisen from actual defaults but rather from credit migrations combined with widening of credit spreads and the loss of liquidity, applying an incremental risk charge covering default risk only would not appear adequate. (BCBS, 2008:1)

In addition, the method proposed for the calculation of trading book credit risk:

for positions covered by the IRC, the incremental capital charge would represent an estimate of the trading book's overall exposure to certain risks over a one-year capital horizon at a 99.9 per cent confidence level, taking into account liquidity horizons of individual positions or sets of positions. (BCBS, 2008:1)

By introducing IRC, the BCBS now require that banks (which qualified for IRB approaches) apply the same capital charge standards to credit-related portfolios in the trading book as they do in the banking book (BCBS, 2008:1). Once the BCBS has finalised the revised requirements, banks must be compliant by 1 January 2010, while banks are allowed an additional year to incorporate IRC into their capital charge-modelling process. The BCBS, however, assured banks that they will not only conduct a two-stage quantitative impact study to test these proposals, but will continue to work together with individual firms as well as industry groups during and after the comment period. This is aimed at refining the proposed changes and to support regulators in implementing these new proposals (BCBS, 2007:1). Results from the first quantitative impact study are now available Bank for International Settlements (BIS), 2007:36) and indicate that, on average, banks will experience a three to fourfold increase in their capital requirements for the trading book.

In January 2009, the BCBS (2009:2) proposed additional requirements for credit exposures in the trading book with the introduction of a stressed $\mathrm{VaR}$ requirement. As losses in banks' trading books during the financial crisis in $2007 / 08$ have increase to a level which is higher than the minimum capital requirements under the Pillar 1 market risk rules, the BCBS will require banks to calculate a stressed VaR by taking into account a oneyear observation period relating to significant losses. This would be in addition to the VaR based on the most recent one-year observation period. This article incorporates these requirements in the empirical capital calculations as 
the calculated market risk charge is calculated with stressed market element built into the modelling process.

The BCBS (2009:2) also proposes to:

discontinue the preferential treatment of a 4 per cent capital charge for specific risk of equities that is currently applicable to portfolios that are both liquid and welldiversified. As a result, an 8 per cent capital charge for specific risk of equities would apply in all cases.

In addition to the BCBS' (2009:2) proposed changes, it vowed to initiate a longer-term, fundamental review of the risk-based capital framework for trading activities.

The impact of the changes to the current regulatory framework, with specific reference to market risk, is explored in the next section. If the changes result in a considerable increase of regulatory capital (as warned by the International Swaps and Derivatives Association (ISDA) (2008:2)), the levels of economic capital would also change dramatically if based on the principles of regulatory capital calculations. The impact of overly punitive regulatory capital charges on banks could be devastating (ISDA, 2008:3). In the economic downturn, this could lead to even less liquidity in the market, which might not necessarily be effective and correct.

New components to the capital charge in the trading book have altered Equation 1 (BCBS, 2007:4) which may now be written as:

$$
\begin{aligned}
& \underbrace{\text { Trading book capital }}=\text { General market risk }+\underbrace{\text { Specific market risk }} \\
& \text { Market risk } \underbrace{\text { Specific }}_{\text {Default risk + Price risk }} \\
& =k \times \mathrm{VaR}_{99 \%}^{10 \mathrm{~d}} \quad+\underbrace{\text { Specific market risk }}_{\text {Default risk }+ \text { Price risk }}
\end{aligned}
$$

has now changed to:

Trading book capital $=$ General market risk + Specific market risk + Stressed VaR $+I R C$

$$
=k \times \operatorname{VaR}_{99 \%}^{10 \mathrm{~d}} \quad+\text { Specific market risk }+k \times \mathrm{SVaR}_{99 \%}^{10 \mathrm{~d}}+\mathrm{CVaR}_{99.9 \%}^{250 \mathrm{~d}}
$$

Note that the incremental risk charge, $I R C=\mathrm{CVaR}_{99.9 \%}^{250 \mathrm{~d}}$, i.e. the capital charge for credit-risky securities present in the trading book, is measured to the same degree of severity (i.e. at the 99.9 per cent confidence level over a full one-year period) as creditrisky securities in the banking book. The new stressed VaR component, $\mathrm{SVaR}_{99 \%}^{10 \mathrm{~d}}$, has been included to account for unexpected swings in market volatility and will be based on severe historical market turbulence, but has been accused of 'double-counting' actual portfolio $\mathrm{VaR}$ and resulting in even higher trading book capital charges.

Banks had to comply with the proposed 2007 guidelines for calculating capital for IRC in the trading book in order to receive specific risk model recognition (BCBS, 2007). The BCBS requested public feedback on the proposed consultative paper before mid February 2008 and ISDA (2008:2) raised their concerns to the BCBS in an official response (Benyon, 2007:1).
Market participants stated that the rules would raise regulatory trading book capital to punitive levels, stunt the development of risk models and even kill off entire business lines (Pengelly, 2009:17). ISDA expressed concern that the proposed IRC charges would have a large impact on the regulation of banks' trading books as the capital charge for market risk is expected to rise considerably compared to current market risk-capital charges (ISDA, 2008:2). Their findings were based on an ISDA study into the impact of the proposed IRC performed on seven international banks which contributed information and technical expertise to assist with the study (ISDA, 2007:1).

Banks' failure to align IRC proposals with the existing capital charge for market risk could have a detrimental effect as firms which are active in the current market turmoil could potentially be distracted by the danger of default risk and not focus on the relevant and important elements of market risks (ISDA, 
2008:2). This could happen if banks allocate too much effort and resources for managing risks that ISDA do not consider being key drivers of economic losses and therefore this would not encourage prudent risk management of trading book portfolios. ISDA asserted that the proposed IRC charge consisting of a oneyear capital horizon with a 99.9 per cent confidence interval to be added to the existing market risk charge is unrealistic and almost certainly fails any 'use test' (ISDA, 2008:3).

Having established a broad background to the problems surrounding the effective measurement of trading book capital and both the BCBS and the industry's response to these problems, the next section proposes a methodology to ascertain an empirical creditholding period, for use in the trading book to more accurately align trading book losses with capital charges.

\section{3}

\section{Methodology}

The methodology used in this article is to apply all the relevant market-risk concepts including the recent development in IRC to design a model for trading book capital based on the prescriptions of the BCBS. This involves using the BCBS prescription and applying the same level of mathematical rigour for trading book capital calculation as used in the banking book.

ISDA (2008:03) concluded that BCBS' proposed requirement of a 99.9 per cent confidence interval over a full year (250 trading days) holding period for credit risk assets in the trading book is too onerous, and asserted an alternative proposal by recommending that it should be reduced to a 60-day holding period with the same confidence interval. ISDA claimed that not only would their proposal reduce trading book capital charges to more realistic levels, but the idea also makes mathematical sense as the governing capital charges equations are reduced to identical bases as well as identical scaling factors (BCBS, 2007:4). Ignoring specific market risk in Equation 2 (which is common to capital charges pre and post the financial crisis in 2007/08):

$$
\underbrace{\text { Trading book capital }}_{\text {Market }+ \text { credit risk }}=k \times \mathrm{VaR}_{99 \%}^{10 \mathrm{~d}}+k \times \mathrm{SVaR}_{99 \%}^{10 \mathrm{~d}}+\mathrm{CVaR}_{99.9 \%}^{250 \mathrm{~d}}
$$

ISDA, however, (2007:7) observed that:

$$
\begin{aligned}
\operatorname{CVaR}_{99.9 \%}^{60 \mathrm{~d}} & =\mathrm{CVaR}_{99 \%}^{10 \mathrm{~d}} \times\left[\sqrt{6} \times \frac{N^{-1}(99.9 \%)}{N^{-1}(99 \%)}\right] \\
& =\mathrm{CVaR}_{99 \%}^{10 \mathrm{~d}} \times[3.25] \\
& \approx k \times \mathrm{CVaR}_{99 \%}^{10 \mathrm{~d}}
\end{aligned}
$$

where $k$ is of the same magnitude (and approximately the same size) as the standard scaling factor $k$ used in traditional market risk regulatory capital calculations, i.e. $3 \geq k \geq 4$. This is not a coincidence: ISDA aimed to obtain a scaling factor of between three and four for the credit risk component as well and then reverse-engineered the holding period of 60 days. This allows Equation 3 to be conveniently and mathematically elegantly rewritten as:

$$
\underbrace{\text { Trading book capital }}_{\text {Market }+ \text { credit risk }}=k \times\left(\operatorname{VaR}_{99 \%}^{10 \mathrm{~d}}+\mathrm{SVaR}_{99 \%}^{10 \mathrm{~d}}+\mathrm{CVaR}_{99 \%}^{10 \mathrm{~d}}\right) \text { with } 3 \leq k \leq 4 \text {. }
$$


Note that all components are measured over a period of 10 days at a 99 per cent confidence interval and scaled by the same $k$ factor. Note also that this is only possible if a holding period of 60 days is chosen for the determination of credit risk capital. The choice of a 60 day holding period is to introduce less stringent capital charges for the credit component of market risk, but it has been achieved through mathematical manipulation (only) of Equation 3, and is otherwise entirely arbitrary: there is no empirical reason for the choice of a 60 day holding period. What follows in the remainder of this article is based on empirical data and does not follow the arbitrary approach described by ISDA.

This article attempts to establish the empirical holding period for credit exposure in the trading book under the new capital requirements proposed by the BCBS. An empirical holding period level will enable banks to ascertain a fair level of economic capital for the trading book by applying the same mathematical standards as prescribed by the BCBS. The holding period was specifically selected as the LGD, correlation and equations prescribed by Basel II cannot be changed in order to determine a fair level of economic capital. The only element in capital calculation that can potentially be adjusted is the probability of default (PD). While the PD itself cannot be changed, the period over which it is valid $^{5}$ can be investigated and adjusted (Algorithmics, 2008: A6). Adjusting the period over which PDs operate adjusts the holding period - thus these can be altered until the capital charges equal the maximum losses experienced by banks immediately after the financial crisis in 2007/08 (and ongoing) in the trading book. Once this 'empirical' holding period has been determined, banks may use it as their economic capital calculation guide. This study assumes that banks wishing to utilise this technique have been approved for AIRB approach.

To measure general market risk, the Monte Carlo technique of measuring portfolio VaR was used to simulate 10000 interest rate scenarios (for bonds and interest rate- dependent derivatives) and 10000 equity returns and prices (for equities and equity derivatives) - see Section 4 for details. In addition, a confidence interval of 99 per cent, a holding period of 10 days and a $k$ factor of 3.5 were used for all portfolios. Specific market risk charges - being common to trading book capital charges both prior to and during the financial crisis in 2007/08 - have been omitted from all calculations. These values were estimated for all bank trading portfolios and recorded as pre-financial crisis in 2007/08 trading book capital charges for each bank.

Next, the effect of a surge in market volatility (and correlations between instruments) on trading book capital was determined using Equation 3. Essentially, this value is the general market risk $\mathrm{VaR}$ under severely stressed conditions (such as those experienced at the height of the financial crisis in 2007/08) multiplied by the relevant $k$ factor. Market volatility during this period surged by a factor of 2.5 in many global instances, correlation structures broke down and ballooned to values approaching +1.0. These stress scenarios were applied to the same 11 international banks' trading portfolios as above and the increase in trading book regulatory capital recorded.

Finally, incorporating credit risk into the estimation (Equation 3) of trading book capital charges was considered. Credit ratings of individual securities were known (or rather, average credit ratings of 'buckets of securities with similar probabilities of default' were known) so associated probabilities of default could be determined. This was accomplished using historical probability of default mappings obtained from Fitch \& Moody's (2009). Knowing average portfolio exposures and PDs and using Basel II's FIRB ${ }^{6}$ allocation of LGDs (e.g. 45 per cent for sovereign exposures) for comparison purposes, credit capital charges could be determined using the Asymptotic Single Risk Factor model results employed by Basel II. For example - the sovereign capital charge calculation is given by (Lamy, 2006:160): 


$$
\text { Credit risk capital }=\mathrm{CVaR} \underset{99.9 \%}{250 \mathrm{~d}}=\sum_{i=1}^{n} E A D_{i} \times L G D_{i} \times\left(N\left(\frac{N^{-1}\left(P D_{i}\right)+\sqrt{\rho_{i}} \cdot N^{-1}(0.999)}{\sqrt{1-\rho_{i}}}\right)-P D_{i}\right) \times M F_{i}
$$

where: LGD is a downturn LGD required by the BCBS. The specific value of 40 per cent was used and is based on the results of the fifth quantitative impact study (BIS, 2007:30). $\mathrm{N}$ is a standard normal distribution with $N^{-1}$ being the inverse of the standard normal distribution. $\rho$ is the asset correlation and is calculated according to the prescriptions of the BCBS (2005b:13). The equation used to calculate the correlation for corporate bonds to be used in Equation 5 is:

$$
\rho=3 \% \cdot \frac{(1-\exp (-x \cdot P D))}{(1-\exp (-x))}+16 \% \cdot\left[1-\frac{(1-\exp (-x \cdot P D))}{(1-\exp (-x))}\right]
$$

where: $\mathrm{x}$ is 50 . The asset correlation for corporate bonds consists of two limiting correlations: 12 per cent and 24 per cent that represent extreme high and low PDs (100 per cent and 0 per cent respectively) and are modelled by an exponential weighting function which indicates the dependency on the PD. The pace at which the exponential function decreases is determined by a factor, specified by the BCBS, called the $x$-factor. This $x$ - factor has an assigned value of 50 for corporate exposures (BCBS, 2005b:13). $M F_{i}$ is the maturity scale factor. A bank's credit portfolio consists of instruments with different maturities. Short-term credit is less risky than in the long term resulting in increased capital requirements for credit instruments with higher maturity (BCBS, 2005b:9). The maturity factor is calculated as prescribed by Basel II by using Equation 7 specified for bonds:

$$
S F_{\text {MATURITY }}=(1-1.5 \times b(P D))^{-1} \times(1+(M-2.5) \times b(P D))
$$

where: PD is determined by the BCBS (2006:279) prescribed risk buckets and $b(P D)$ is a smoothed (regressed) maturity adjustment (smoothed over PDs) calculated using Equation 8 (BCBS, 2005b:11):

$$
b(P D)=(0.11852-0.05478 \times \log (P D))^{2}
$$

Credit capital charges were determined for all credit-risky instruments each of the 11 banks' trading books portfolios and the increase in trading book regulatory capital again recorded.

The financial crisis in 2007/08 arguably precipitated the most severe losses in banking history. Given this severity, it is unlikely that such a calamitous event will occur again anytime soon - and even if it were to do so, the nature of the event would be manifest via a different set of circumstances, and affect bank loss frequency and severity in an entirely different way (Picerno, 2011:1). For the foreseeable future, then, bank empirical losses measured during the financial crisis in 2007/08 could be seen to reflect 'worst case losses' or a $1: 1000$ event. If regulatory capital for the trading book is in excess of these losses, it may be argued that it is too punitive since this amount of capital is protecting the bank from losses that are so unlikely as to be negligible. The aim here, then, is to adjust parameters of the relevant capital equations in such a way as to increase/decrease the trading book regulatory capital until it is roughly equal to the average of the five largest losses of the 11 banks. Of the parameters which contribute to Equation 5, only the PDs may be altered. Maturities and LGDs are fixed (and the latter are downturn values in any case), and asset correlations depend entirely upon PDs (so changing PDs automatically changes the asset correlation). PDs may not be changed at the practitioner's whim, of course; these are 
measured values. However, the PDs banks measure are - unless otherwise defined always annual PDs. This is the way in which intrinsic 'holding periods' are embedded into credit risk calculations. Thus, to 'change' PDs, only the 'holding period' may be adjusted - to, say, a six month PD or a nine month PD. Adjusting the period over which the PDs are measured automatically adjusts the PDs themselves (except they will no longer be annual PDs so the credit risk calculations will now measure the credit risk inherent in securities held for the relevant period).

PDs measured over periods less than one year are difficult to observe, but banks may scale annual PDs to reflect longer or shorter holding periods. Assuming the liquidity horizon for a particular security is six months, the PD may be scaled down by first noting that the probability of NOT defaulting in one year $\equiv$ probability of surviving for 250 days (ISDA, 2008:3), i.e.:

$$
P D_{x \mathrm{~d}}=1-S_{x \mathrm{~d}}
$$

and (e.g.)

$$
S_{1 \mathrm{~d}}=\left(S_{250 \mathrm{~d}}\right) \frac{1}{250},
$$

where $P D_{x \mathrm{~d}}$ is the $x$-day probability of default and $S_{x \mathrm{~d}}$ is the $x$-day probability of survival.

For a period of $x$ days, Equation 10 gives:

$$
S_{x \mathrm{~d}}=\left(S_{250 \mathrm{~d}}\right) \frac{x}{250}
$$

and substituting into Equation 9 gives:

$$
\begin{aligned}
& P D_{x \mathrm{~d}}=1-\left(S_{250 \mathrm{~d}}\right) \frac{x}{250} \text { or } \\
& x=250 \cdot\left(\frac{\ln \left(1-P D_{x \mathrm{~d}}\right)}{\ln S_{250 \mathrm{~d}}}\right) .
\end{aligned}
$$

The procedure is now relatively straightforward. For any bank, both the empirical capital required (estimated from the average of largest losses experienced) and the regulatory (Basel II) trading book capital (using Equation
3 with CVaR 250 d , Equation 5) are known. The PDs in Equation 5 are adjusted ${ }^{7}$ until these two amounts are equal; this provides the requisite $P D_{x \mathrm{~d}} \cdot{ }^{8}$ Knowing annual PDs (hence the annual probabilities of survival, $S_{250 \mathrm{~d}}$ ), the values of $x$ may be determined using Equation 12 for each security. Most banks' traded securities range between $0.03 \% \geq P D \geq 5 \%$, and the equivalent $x$ 's vary by only $\pm 2 \%$. Thus, for all intents and purposes, a single $x$ is extracted from the above procedure. This is the requisite, empirical, holding period.

\section{4}

\section{Data and results}

In order to compare the BCBS's standards with the actual experiences in banks, this study used loss data from some large UK and European banks (all of whom have been approved for the AIRB credit risk capital approach). Where publicly available data (such as asset return series) were required, these were obtained from third party data sources such as Bloomberg $^{\mathrm{TM}}$ or Reuters ${ }^{\mathrm{TM}}$. However, some data, while not disclosed to market participants, were available to the authors. Such privileged data have been disguised to conceal the source. Where necessary, permission to present analytical results without data source disclosure was sought from data owners.

The trading book portfolios ${ }^{9}$ of five large UK banks and six large European banks were evaluated. VaR (and capital requirements) for these portfolios were measured pre-crisis ${ }^{10}$ and these values compared with capital charges for the trading book after taking into account (a) increased volatility measured during the most volatile period of the financial crisis in 2007/08 and (b) the new IRC capital charges. ${ }^{11}$ The latter capital charges were then compared with worst-case, actual bank loss experience in trading books calculated during the financial crisis in 2007/08. If the values compare favourably, Basel II capital charges may be considered - in some sense - 'fair' since the financial crisis in 2007/08 is widely considered to be the most severe market event for several decades. If the Basel II capital charges are onerous compared with actual, measured 
losses then assertions of punitive charging for trading book portfolios may be justified and an attempt to calibrate these disparate values should be undertaken. Note that although the exact constituents of the banks' trading portfolios were not known (at least, not on an individual position basis), a broad overview of asset class information was provided for analysis. These data provided a breakdown by market value of all asset classes in the trading books, e.g. equities, commodities, interest bearing securities and derivative positions. General market risk for these portfolios was measured using the Monte Carlo VaR technique whereby $10 \quad 000$ interest rate scenarios (for bonds and interest rate- dependent derivatives) and 10000 equity returns and prices (for equities and equity derivatives) were simulated and the portfolio profit and loss distribution (P\&L) analysed. A stressed VaR was determined assuming a -2 standard deviation move away from historical average $P \& L$ values. Credit risk capital was measured using Equation 5 for those securities deemed subject to credit events such as default, credit rating transitions and loan restructuring.

The components of the comparison calculation are shown below, rebased to one pre-financial crisis in 2007/08 for each bank for ease of comparison.

Table 1

Effect of new Basel II rules governing trading book capital charges.

\begin{tabular}{|c|c|c|c|c|c|}
\hline & & \multicolumn{4}{|c|}{ Trading book capital: } \\
\hline \multirow{3}{*}{\multicolumn{2}{|c|}{ Bank }} & \multirow{3}{*}{$\begin{array}{l}\text { Pre } \\
\text { crisis }\end{array}$} & \multicolumn{3}{|c|}{ During crisis } \\
\hline & & & \multicolumn{2}{|c|}{ Simulated } & \multirow{2}{*}{$\begin{array}{c}\text { Empirical } \\
\text { Average } 5 \text { largest } \\
\text { exceptions recorded }\end{array}$} \\
\hline & & & $\begin{array}{c}\text { Stressed VaR } \\
\text { only }\end{array}$ & $\begin{array}{l}\text { Stressed VaR } \\
\text { + credit capital }\end{array}$ & \\
\hline \multirow{5}{*}{ 号 } & 1 & \multirow{5}{*}{1.00} & 1.83 & 3.55 & 2.48 \\
\hline & 2 & & 1.64 & 3.57 & 2.63 \\
\hline & 3 & & 1.59 & 4.09 & 2.72 \\
\hline & 4 & & 1.92 & 3.72 & 2.47 \\
\hline & 5 & & 2.10 & 4.14 & 2.94 \\
\hline \multirow{6}{*}{ 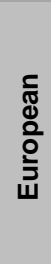 } & 6 & \multirow{6}{*}{1.00} & 2.97 & 4.33 & 3.01 \\
\hline & 7 & & 2.60 & 3.46 & 2.75 \\
\hline & 8 & & 2.22 & 4.84 & 2.80 \\
\hline & 9 & & 3.33 & 3.74 & 2.76 \\
\hline & 10 & & 2.23 & 4.63 & 2.50 \\
\hline & 11 & & 2.17 & 3.93 & 2.46 \\
\hline
\end{tabular}

Source: Compiled by the authors.

The average increase in total trading book capital charges (i.e. including both stressed $\mathrm{VaR}$ charges and credit risk capital charges) is $4.00 \times$ the original capital charge before the onset of the financial crisis in 2007/08. The average of the five largest exceptions measured by each bank during the financial crisis in $2007 / 08$ to date appears in the last (sixth) column of Table 1: the average of the column measured for all 11 banks was $2.68 \times$. These results are shown in Figure 2, for both sets of banks. For each bank, the simulated capital under the new Basel II exceeds the average of the banks' five worst losses measured during the financial crisis in 2007/08 market turbulence. 


\section{Figure 2}

Increase in required capital using the new Basel II trading book capital charges amendments and average five worst losses measured during the financial crisis in 2007/08 for each bank. Capital required pre-crisis $=1$

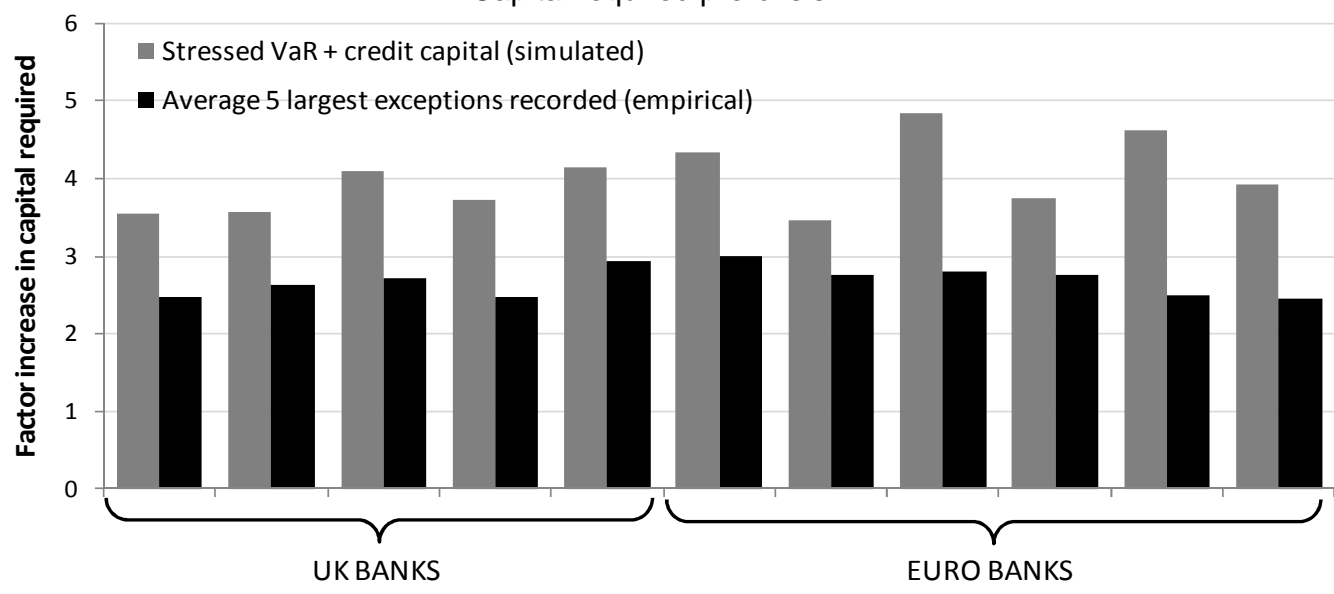

Source: Fitch \& Moody's (2009)

Using these averages, broad, UK and Euro average empirical holding period may be deduced. The stressed VaR + credit capital values are, on average $1.49 \times$ higher (= $4.00 / 2.68$ ) than the average of the five worst observed losses in these banks measured over the financial crisis in 2007/08. The PDs for each portfolio are adjusted until the stressed $\mathrm{VaR}+$ credit capital values $=$ the average of the five worst observed losses, i.e. until this ratio $=1.00$. The PD for each portfolio needed to be reduced by a factor of $\approx 2.56$ using a Newton-Raphson method. Using Equation 9, the new 'empirical' holding period was measured and found to be $\approx 97$ days, rounded up to 100 days for simplicity.

Credit capital charge results are shown in Figure 3, for three scenarios. These are credit capital charges using: actual annual PDs, PDs determined over a 100 day holding period (empirically observed) and PDs determined over a 60 day holding period (as suggested by ISDA). The annual PD range reported in Figure 3 is $0.001 \% \leq P D \leq 2 \%$. The trends observed in Figure 3 persist for $P D \geq 2 \%$, but are excluded for clarity.

Figure 3

Capital charges for actual annual PDs, PDs valid over 100 days (empirical) and PDs valid over 60 days (ISDA)

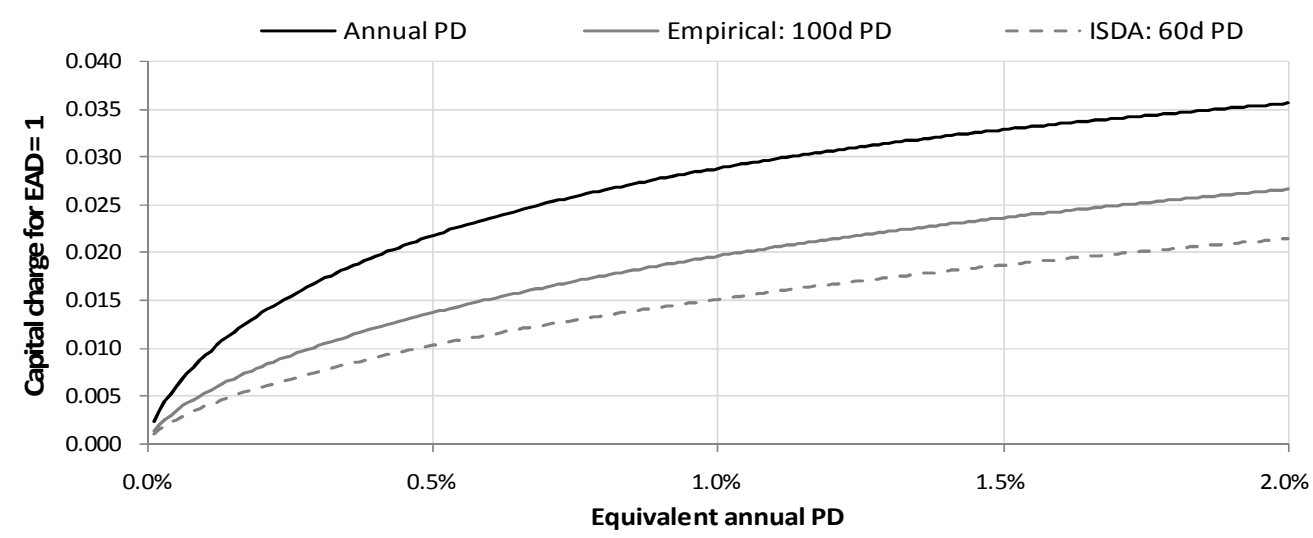

Source: Compiled by the authors. (2010). 


\section{5}

\section{Conclusion}

Given the global financial crisis in 2007/08 that shocked markets worldwide, the role of risk managers and regulators will almost certainly change. This will involve increased prominence and authority of bank regulation and a complete reshuffling of the way in which risks are measured. What will become increasingly critical for banks is to understand the risks they face given the underlying risk environment.

This article therefore investigated the effect of new regulatory capital requirements on banks, specifically the new requirements pertaining to credit risk in the trading book (via the 'incremental risk charge' or IRC). The investigation was conducted by firstly introducing a calculation methodology which allow banks (of any size and complexity) to determine, empirically, their own unique parameters from their own unique loss experience. Knowing these empirical values allow banks to ascertain whether or not the BCBS-specified fixed parameters ensure that capital requirements are indeed too lenient or too onerous.
The first parameter which has deliberately been fixed by the BCBS as a means of introducing and establishing the necessary austerity into capital requirement formulas is asset correlation. For the investigated banks in this article, the average increase in total trading book capital charges was $4 \times$ the original capital charge before the onset of the financial crisis in 2007/08. Also, for each bank, the simulated capital under the new Basel II exceeds the average of the banks' five worst losses measured during the financial crisis in 2007/08 market turbulence, reflecting a high perhaps even punitive - measure of conservatism imposed by Basel II.

Similar to the above, where empirical parameters (asset correlation) were calculated to determine the fair capital charge for credit risk, the empirical holding period was determined for market risk. The increase in capital, based on the fixed, Basel II holding period, again indicates the austerity of the new regulatory rules, and the recent industry criticism regarding the inflexibility of the regulatory capital approach therefore seems to be justified by the results of this article.

\section{End notes}

1 Economic capital is the amount of capital a bank needs to cover losses arising from the unique risk exposure at a specific confidence level. This capital requirement is calculated based on the bank's own dynamic, internal measures, not prescribed by any external parties (Smithson, 2008). Economic capital has reached an advanced level of maturity, and is now more widely accepted than ever before (Singh \& Wilson, 2007:19).

2 There is a direct association between the number of exceptions (the number of outliers or P\&L values in excess of the VaR forecast, measured over a one year period. 'Outliers' here refers to the number of points over and above those predicted to be in excess of $\mathrm{VaR}$ prescribed by the confidence interval) and the value of the regulatory scaling factor, $k$. Up to four exceptions, for example, results in $k=3.0$, five exceptions gives $k=3.4$ and ten or more, $k=4.0$. If the number of exceptions falls into the 'red zone' (which indicates deeper problems with a bank's market risk model) local regulators automatically assign $k$ a value of 4.0 (BCBS, 2006:318).

3 This is based on the possibility that the qualitative and quantitative criteria might not be sufficient during periods of severe or prolonged market movements. The scaling factor is not a substitute for regular stress testing. The BCBS have argued that the scaling factor is directly related to the performance of a bank's internal model. It therefore introduces a built-in positive incentive which rewards an accurate and highly predictive model. The scaling factor has also been designed by the BCBS to compensate for potential weaknesses in the internal modelling process (BCBS, 1996: 3 ).

4 In this study, default (with regard to a particular obligor) is considered to have occurred when - as it is in Basel II lexicography (BCBS, 2006:100) - either or both of the two following events have taken place: (a) the bank considers that the obligor is unlikely to pay its credit obligations to the banking group in full, without recourse by the bank to actions such as realising security, and (b) the obligor is past due more than 90 days on any material credit obligation to the banking group.

5 PD is always measured annually unless otherwise stated (Sueyoshi, 2006:207)

6 Foundation Internal Ratings Based approach.

7 Using, for example, a Newton-Raphson method.

8 Although there are as many PDs as there are credit securities, all annual PDs of all positions are adjusted by the same scale factor to ensure equality of regulatory required capital and empirically determined losses.

9 Comprising equities, corporate and government bonds (with and without embedded optionality), credit default and total return swaps and several other derivatives (both interest rate and equity).

10 This is simply a combination of general market risk $(\mathrm{VaR})$ and specific market risk - from Equation 1.

11 Effectively the full gamut of new trading book capital charges. 


\section{References}

ADRIAN, T. \& SHIN, H.S. 2009. Liquidity and leverage. Federal Reserve Bank of New York. Staff Report no. 328.

ALENTORN, A. \& MARKOSE, S. 2008. Generalized extreme value distribution and extreme economic value at risk (EE-VaR) in Computational methods in financial engineering. Essays in Honour of Manfred Gilli, Kontoghiorghes, E.J., Rustem, B.\& Winker, P. (eds.) Springer verlag: Berlin Heidelberg pp.47-71.

ALGORITHMICS QUANTITATIVE RESEARCH GROUP INCORPORATED. 2006. Losing default correlations, step by step. Press release in October [Online] Available at: http://www.bis.org/publ/ bcbs14041/ca/algorithmics.pdf [Accessed 2008-12-05].

BAKHSHI, B.S. 2007. Risk information: disclosure and use. Speech at Risk Management Investor Day, Credit Suisse, London. 22 May.

BAKSHI, S. 2004. Basel norms: challenges in India. The Charted Accountant, 53(4):426-432.

BANK FOR INTERNATIONAL SETTLEMENTS. 2007. Fifth quantitative impact studies (QIS 5): Overview of documents [Online] Available at: http://www.bis.org/bcbs/qis/index.htm [Accessed 2007-04-09].

BCBS. 1995. An internal model-based approach to market risk capital requirements [Online] Available at: http://www.bis.org/publ/bcbs17.pdf [Accessed 2008-08-29].

BCBS. 1996. Overview of the amendment to the capital accord to incorporate market risks [Online] Available at: http://www.bis.org/publ/bcbs23.pdf [Accessed 2011-01-31].

BCBS. 2004. International convergence of capital measurement and capital standards: a revised framework. Basel, Switzerland, June.

BCBS. 2005a. Amendment to the capital accord to incorporate market risks (2005 Update) [Online] Available at: http://www.bis.org/publ/bcbs119.pdf [Accessed 2007-09-12].

BCBS. 2005b. An explanatory note on the Basel II IRB risk weight functions [Online] Available at: http://www.bis.org/bcbs/irbriskweight.htm [Accessed 2008-03-02].

BCBS. 2006. International convergence of capital measurement and capital standards: a revised framework (comprehensive version). Basel, Switzerland, June.

BCBS. 2007. Guidelines for computing capital for incremental default risk in the trading book - consultative document [Online] Available at: http://www.bis.org/publ/bcbs134.htm [Accessed 2008-09-12].

BCBS. 2008. 'Computing capital for incremental risk in the trading book' and 'revisions to the Basel II market risk framework' - consultative documents [Online] Available at: http://www.bis.org/press/ p080722.htm [Accessed 2008-08-12].

BCBS. 2009. Revisions to the Basel II market risk framework - consultative document. Press release in January [Online] Available at: http://www.bis.org/publ/bcbs148.pdf?noframes=1 [Accessed 2009-03-30].

BENYON, D. 2007. Market risk regulatory capital expected to rise. oprisk \& compliance [Online] Available at: http://www.opriskandcompliance.com/public/showPage.html?page=477008 [Accessed 2008-11-22].

BERKOWITZ, J. \& O'BRIEN, J. 2002. How accurate are the value-at-risk models at commercial banks? Journal of Finance, 57(3):1093-1111. June.

BLOOMBERG. 2009. FTSE100 daily returns [Online] Available at: http://www.bloomberg.com/apps/ quote?ticker=UKX:IND [Accessed 2009-12-09].

DVORAK, M. 2005. The uses and misuses of required economic capital [Online] Available at: http://www.isda.org/c_and_a/ppt/Uses-and-Misuses-of-Required-Economic-Capital11-15-05.ppt [Accessed 2009-11-28]

FINANCIAL STABILITY FORUM (FSF) \& BASEL COMMITTEE OF BANKING SUPERVISION (BCBS) WORKING GROUP. 2009. Joint FSF-BCBS working group on bank capital issues: reducing procyclicality arising from the bank capital framework. March [Online] Available at: http://www.fsforum.org/ publications/r_0904f.pdf?noframes=1 [Accessed 2009-03-30].

HARTZ, C., MITTNIK, S. \& PAOLELLA, M. 2006. Accurate value-at-risk forecasting based on the normal. GARCH model. Computational Statistics \& Data Analysis, pp. 2295-2312. 
HBOS. 2009. HBOS comments on 'Proposed revisions to the Basel II market risk framework' and 'Guidelines for computing capital for incremental risk in the trading book' [Online] Available at: http://www.bis.org/ publ/bcbs14041/ca/hbosirt.pdf [Accessed 2009-11-28].

INTERNATIONAL SWAPS AND DERIVATIVES ASSOCIATION, INC (ISDA). 2007. IDR impact study. Final version. 13 July:1-12.

INTERNATIONAL SWAPS AND DERIVATIVES ASSOCIATION, INC (ISDA). 2008. Industry response to BCBS consultative document 'Guidelines for computing capital for incremental default risk in the trading book.' February.

JORION, P. 2000. Value at Risk: the new benchmark for managing financial risk. McGraw Hill: New York. LAMY, M. 2006. The treatment of credit risk in the Basel accord and financial stability. International Journal of Business, 11(2):159-170.

MERRILL LYNCH. 2008. [Available on the Internet:] http://newsroom.bankofamerica.com/index.php?s=43 [Accessed 2009-01-12].

MOODY'S KMV. 2009. Stand-alone credit risk measures. [Online] Available at: http://www.moodyskmv. com/products/standAlone_creditRisk.html [Accessed 2009-12-05].

NAZARETH, A.L. 2007. Remarks from the US Securities and Exchange Commission. Speech given before the Securities Industry and Financial Markets Association (SIFMA) Risk Management Conference, New York, 27 June.

PENGELLY, M. 2009. The bank capital burden. Risk Magazine, 01 July:17-20.

PICERNO, J. 2011. Worrying about inflation. Again. [Online] Available at: http://seekingalpha.com/ article/251457-worrying-about-inflation-again [Accessed 2011-02-28].

PROCTOR, C. 2006. Basel II: credit risk mitigation. Bird \&Bird, 18 October [Online] Available at: http://www.thehindubusinessline.com/iw/2005/02/06/stories/2005020600621300.htm http://www.twobirds.com/english/publications/ [Accessed 2007-06-11].

SINGH, R. \& WILSON, T. 2007. Insights from the joint IFRI/CRO forum survey on economic capital practice and applications. International Financial Risk Institute, Geneva, Switzerland.

SMITHSON, C. 2008. Economic capital ideas. Press release in June 2008 [Online] Available at: http://www.risk.net/public/showPage.html?page=799002 [Accessed 2008-09-23].

SUEYOSHI, T. 2006. An integrated view of risk management: Portfolio allocation incorporating credit risk. International Journal of Operations Research, 3(3):183-197.

VAN DE VENTER, T.W.G. 2000. Backtesting historical simulation value-at-risk for a selected portfolio of South African bonds. Research Journal of the School of Accounting Sciences, 8:183-197.

WONG, M. 2008. Bank capital budgeting after Basel II [Online] Available at:

http://www.corporateportfoliomanagement.org/article-17-Bank-Capital-Budgeting-After-Basel-II [Accessed 2009-09-17].

ZHANG, J., ZHU, F. \& LEE, J. 2008. Asset correlation, realized default correlation, and portfolio credit risk - Modelling methodology, Moody's KMV Company. Press release in March. [Online] Available at: http://www.moodyskmv.com/research/files/wp/Asset_Correlation_and_Portfolio_Risk.pdf [Accessed: 2009-03-30]. 